\title{
A INTERPRETAÇÃO DO "TESTAMENTO" SOB A ÓTICA DO DIREITO PORTUGUÊS
}

\author{
Patrícia Fontanella ${ }^{1}$
}

Resumo: O testamento é fato designativo pelo qual o testador, em razão de sua autonomia, designa seus sucessíveis a partir de uma declaração com conteúdo patrimonial e/ou extrapatrimonial, que produzirá efeitos após a sua morte. Seus efeitos tem a sua causa na morte do autor, motivo pelo qual o momento de sua realização e o momento da abertura da sucessão revestem-se de grande importância jurídica para a verificação dos valores subjacentes ao testamento e determinação do sentido e do alcance correspondentes à real intenção do disponente. O presente estudo visa a contribuir com as discussões relativamente às particularidades da interpretação dos testamentos, em especial, ao esclarecimento do conteúdo volitivo da declaração do de cuius, de modo a determinar os efeitos que serão produzidos em atenção aos fins por ele desejados.

Palavras-chave: Interpretação dos testamentos. Negócio jurídico testamentário. Testamento.

\section{INTRODUÇÃO}

O respeito pela determinação das pessoas que faleceram representa um "imperativo civilizacional,"2 que exige do intér-

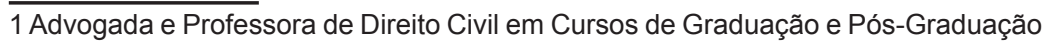
em Direito. Professora das Escolas da Magistratura e do Ministério Público de Santa Catarina. Mestre em Ciência Jurídica pela UNIVALI e Doutoranda em Instituições Jurídico-Civis pela Universidade de Lisboa (FDUL). E-mail: patricia@ patriciafontanella.adv.br

2 OLIVEIRAASCENSÃO, José de. Teoria geral do negócio jurídico e o negócio testamentário. In: Revista da Faculdade de Direito da Universidade de Lisboa. Coimbra: Coimbra Editora, 2003, p. 33. 
prete $^{3}$ uma análise criteriosa das disposições testamentárias e soluções próprias quanto à sua interpretação. As características peculiares dessa exteriorização de vontade, a análise da relação entre a vontade testamentária e o contexto do testamento, eventual recurso à prova complementar e a relevância dos interesses de terceiros são temas que se destacam e que a doutrina e a jurisprudência há muito discutem.

O caso típico ${ }^{4}$ para este estudo é o seguinte: imagine-se estar diante de um testamento, em que a de cuius (divorciada e sem filhos) tenha deixado a parte disponível de seus bens para a sua mãe com expressa menção de, em 'caso de morte simultânea delas' ou 'até em caso de dúvidas', aos primos caberia a deixa testamentária, tendo sido entrelinhadas as expressões 'delas' ou 'até em caso de dúvidas'. No entanto, a irmã unilateral consanguínea reclama a totalidade da herança, alegando a caducidade da disposição, tendo em vista o falecimento da beneficiária anteriormente à testadora. ${ }^{5}$

A questão para a qual se procurará uma resposta pode enunciar-se nos seguintes termos: é possível considerar-se válida e vigente a cláusula testamentária que beneficia os primos? E, em caso afirmativo, esta deixa testamentária corresponderá à totalidade da herança ou apenas a quota disponível?

3 Por intérprete referimo-nos neste trabalho "ao juiz, que é aquele que tem de olhar para o ordenamento jurídico para enxtrair dele um sentido, a fim de o aplicar num caso concreto. Mas intérprete também quem argumenta para defender o seu cliente, como é o caso do advogado, quem ensina o Direito, visando, neste caso, determinar um sentido da ordem jurídica em abstracto, sendo esse fim visado pela tarefa interpretativa do professor de Direito". ESTEVES, Jorge Manuel A. De Almeida. Os limites da interpretação jurídica e a responsabilidade do intérprete. In: Revista Jurídica da Universidade Portucalense, n. 14. Porto, 2010, p. 127.

4 Esta é a situação típica que analisaremos no presente trabalho. O tipo constitui o meio termo entre o geral e o particular, é comparativamente um concreto, um universale in re. O tipo não é definível, mas apenas explicitável. Cfr. KAUFMANN, Arhur. Filosofia do direito. 4 ed. Lisboa: Fundação Calouste Gulbenkian, 2010, p. 186.

50 caso apresentado inspira-se numa situação real objeto do acórdão de 17.04.2012 (ALVES VELHO), do Supremo Tribunal de Justiça Português. Disponível em www. dgsi.pt Acesso em 04.05.2012. 
O Código Civil Português ${ }^{6}$ prevê no artigo $2026^{\circ}$ como títulos de vocação sucessória o testamento, a lei e o contrato. São factos designativos através dos quais alguém fica sucessível porque se beneficia de uma expectativa sucessória ${ }^{7}$, que se perfectibilizará mediante aceitação.

Os artigos $236^{\circ}$ e $237^{\circ}$ do Código Civil estabelecem o regime comum da interpretação dos negócios jurídico e prevê, para os negócios formais, regras particulares no artigo $238^{\circ}$.

Por outro lado, o legislador estabeleceu a base jurídico -positiva da interpretação dos testamentos no artigo $2187^{\circ}$ que, em seu n. 1 dispõe que, na interpretação das disposições testamentárias, deve o intérprete analisar "o que parecer mais ajustado com a vontade do testador, conforme o contexto do testamento." Por força do caráter formal do testamento, o n. 2 deste mesmo dispositivo exige que o sentido deva ter "um mínimo de correspondência no contexto do testamento", representando verdadeiro desafio ao intérprete.

O que interessa, então, é o esclarecimento do conteúdo volitivo da declaração da de cuius, de modo a determinar os efeitos que serão produzidos em atenção aos fins por ela desejados. Assim, indispensável se mostra a interpretação testamentária para a concretização do direito no caso apresentado, ou seja, a atribuição dos bens a quem a testadora realmente desejava.

Inicia-se este artigo tratando de ato e negócio jurídico, a fim de assentar posições para a análise subsequente que enfocará o regime geral da interpretação dos negócios jurídicos. É importante notar que se trará definições apenas para orientação do leitor e não possuem caráter decisivo, eis que "não é fácil encontrar uma definição jurídica que consiga exprimir totalmente a verdade do definido."

6 São do Código Civil Português as normas referidas neste trabalho sem identificação do diploma legal em que se integram, salvo se algo diferente resultar do contexto em que são citadas.

7 OLIVEIRAASCENSÃO, José de. Direito civil. Sucessões. 5 ed., Coimbra: Coimbra Editora, 2000, p. 39.

8 VASCONCELOS, Pedro Pais de. Teoria geral do direito civil. 4 ed., Coimbra: Almedina Editora, p.566. 
A seguir, verificar-se-ão as regras relativas ao testamento na legislação portuguesa, bem como suas características e conteúdo, que se revelam importantes na medida em que a sua qualificação jurídica traz desdobramentos significativos para a interpretação do testamento. Como lembra Betti ${ }^{9}$, o tratamento diferenciado nessa matéria não decorre unicamente da unilateralidade do negócio ou da gratuidade da causa, consideradas em si mesmas, mas do caráter mortis causa da disposição, em que não há conflito de interesses envolvido mas, unicamente, uma relação sucessória entre o defundo e os seus sucessores.

No último tópico, partir-se-á para o estudo da interpretação da declaração negocial testamentária e dos problemas que podem envolver a concretização do pensamento do disponente: a impropriedade das expressões utilizadas, a influência do contexto do testamento e a possibilidade do recurso à prova complementar para esclarecimento desse pensamento.

Por fim, apontaremos as considerações acerca da pesquisa realizada, respondendo ao questionamento formulado.

\section{DOS NEGÓCIOS JURÍDICOS E SUA INTERPRETAÇÃO}

\subsection{Considerações iniciais}

É através das ações que o homem exterioriza intenções para a satisfação de suas necessidades e o Direito, no seu papel regulador valora condutas, fazendo com que um mesmo comportamento humano seja analisado diferentemente, dependendo da intenção e finalidade que move o seu agente. Desse modo, "O que caracteriza a acção é a síntese do comportamento com a sua intencionalidade e o seu fim, num todo incindível, uma unidade que exprime o agir humano." 10

Aos acontecimentos da vida a que o Direito atribui consequências jurídicas dá-se o nome de fatos jurídicos. Nas palavras

9 BETTI, Emilio. Teoria geral do negócio jurídico. Campinas: Servanda Editora, 2008, p. 517.

10 VASCONCELOS, Pedro Pais de. Teoria geral do direito civil, p. 400. 
de Baptista Machado ${ }^{11}$, “(...) o facto jurídico é na verdade o elemento dinâmico que produz alterações na vida jurídica ou no mundo do direito."

Os fatos jurídicos podem ser subdivididos, de acordo com a Teoria Geral do Direito, em atos jurídicos - que se subdividem em atos jurídicos em sentido estrito e negócio jurídico - e fatos jurídicos em sentido estrito. Os primeiros caracterizam-se pela valoração da consciência e vontade livre e os segundos pela irrelevância da valoração da consciência e vontade humanas.

Inicia-se pelo estudo dos atos e negócios jurídicos e, após, passa-se à teoria geral da interpretação dos negócios jurídicos, partindo-se do pressuposto de que a realidade de situações de vida que se apresentam ao intérprete é variável, exigindo a consideração dos tipos à lei subjacente para que se possa dar uma adequada resposta ao conflito existente.

\subsection{Ato e negócio jurídico}

A ação humana é caracterizada como um ato jurídico na medida em que o ordenamento jurídico reconhece a consciência e a vontade livres do agente, atribuindo-lhes valor e conseqüências jurídicas. É a relevância da finalidade do ato perante a ordem jurídica que lhe atribui o caráter de ato jurídico.. ${ }^{12}$

A ordem jurídica possibilita ao particular regular suas relações, estabelecendo-lhes o conteúdo e a respectiva disciplina. Os particulares são titulares de uma esfera de liberdade juridicamente protegida, que decorre do reconhecimento de sua dignidade.

No âmbito do Direito Privado, essa liberdade jurídica da qual o indivíduo dispõe chama-se autonomia: é o direito de reger-se por suas próprias leis e que encontra limites apenas na ordem pública, na boa-fé e nos bons costumes e, conforme

11 BAPTISTA MACHADO, João. Introdução ao direito e ao discurso legitimador. 18 reimpressão. Coimbra: Almedina Editora, 2000, p. 82.

12 OLIVEIRA ASCENSÃO. José de. Teoria geral. Ações e fatos jurídicos. V. 2 . 3 ed., São Paulo: Saraiva Editora, 2010, p. 18. Nesse sentido, também BETTI, Emilio. Teoria geral do negócio jurídico, p. 463. 
anota Cariota-Ferrara ${ }^{13}$, estes limites variam de país a país e de tempos em tempos.

Como exemplo da concretização do Estado de Direito ${ }^{14}$, é a autonomia privada uma "atividade preceptiva, que a ordem jurídica estadual torna sob a sua proteção, acolhendo-se na sua órbita mediante recepção e traduzindo-os em termos de relações jurídicas disciplinadas e configuradas pelas suas normas" ${ }^{15}$.

O Código Civil Português no artigo 295 adotou a teoria dualista ${ }^{16}$ que separa ato e negócio jurídico e a característica fundamental que diferencia os atos e os negócios jurídicos, segundo o nosso entendimento, é a autonomia. Nos negócios jurídicos, a força jurídica decorre da autonomia privada, enquanto nos atos sua força decorre da lei. ${ }^{17}$

Nessa perspectiva, é o negócio uma vinculação jurídica, um comportamento de validade em virtude da qual a autonomia privada confere sentido, tendo como princípio básico

13 CARIOTA-FERRARA, Luigi. El negocio jurídico. Trad. del italiano, prólogo y notas de Manuel Albaladejo. Madrid: Aguilar, 1956, p. 45. Ordem Pública, boa-fé e bons costumes são termos cujo conceito não decorre da lei ou de valorações do legislador. Precisam ser identificadas pelo intérprete no caso concreto através de representações de valor, que se modificam conforme o momento histórico vivido, as transformações sociais e a natureza das coisas e visam delimitar a autonomia de cada pessoa em sua liberdade, equilibrando-a com os interesses comuns. É o que se chama "diálogo entre autonomia e heteronomia no domínio do negócio jurídico." Cfr. VASCONCELOS, Pedro Pais de. Teoria geral do direito civil, p. 422 e LAMEGO, José. Hermenêutica e Jurisprudência. Análise de uma recepção. Lisboa: Fragmentos Editora, 1990, pp. 64-65.

14 LARENZ, Karl. Metodologia da ciência do direito. 3 ed., Lisboa: Fundação Calouste Gulbenkian Editora, 1997, p. 693.

15 BETTI, Emilio. Teoria geral do negócio jurídico, p. 464. Cfr. anota CARIOTA-FERRARA, Luigi: "Vuelve a ser conveniente advertir que la autonomia de la voluntad privada encuentra em su própria esencia y razón de ser los límites dentro de los que se desenvuelve: los interesses proprios. Cada uno puede disponer em su própria casa y no em ajena; respecto de ésta chocaria com La barrera de La igual autonomia del otro sujeito".In: El negocio jurídico, p. 44.

16 Esta teoria ganhou adesão de estudiosos como Giuseppe Stolfi, F. Santoro Passarelli, Roberto de Ruggiero, Giuseppe Mirabelli e Emílio Betti, na Itália; Federico de Castro y Bravo, na Espanha; Ramón Aguila, no Chile; Pontes de Miranda, Orlando Gomes, Miguel Reale e Antonio Junqueira de Azevedo, no Brasil. Cfr. ABREU FILHO, José. O negócio jurídico e sua teoria geral. 5 ed., São Paulo: Saraiva Editora, 2003, pp. 16-30.

17 FERRI, Giovanni. I/ negozio giuridico. Padova: CEDAM Editora, 2001, pp. 37 e ss; LARENZ, Karl. Metodologia da ciência do direito, pp. 421 e ss. e VASCONCELOS, Pedro Pais de. Teoria geral do direito civil, pp. 417-418. 
de interpretação, este seu sentido de instrumento de autovinculação. ${ }^{18}$ É, assim, a autonomia a causa eficiente dos negócios jurídicos, posto serem decorrentes da autolegislação do homem, constituindo-se na origem das situações jurídicas. Nas palavras de Kaufmann"19 "Apenas autônoma e não heteronomamente se podem fundamentar autênticos deveres."

Quando, portanto, realizamos negócios com valia jurídica projetamos uma ação com fins na realidade exterior e que possui limitação nos princípios da responsabilidade e da confiança. Com efeito, à realização desta intenção chamamos declaração negocial ${ }^{20}$.

Essa declaração negocial é valor, com regime e efeitos jurídicos pré-determinados pelas partes. É um "conjunto de relações", ${ }^{21}$ "um fazer humano carregado de sentido" ${ }^{22}$ e cuja interpretação deve se dar a partir de um ponto de vista interno e não de uma perspectiva externa, como anota Lamego. ${ }^{23}$

18 LAMEGO, José. Hermenêutica e jurisprudência, p. 67-68 e FERRI, Giovanni. II negozio giuridico, pp.37-38. Pedro Pais de Vasconcelos em sua Teoria geral do direito civil, p. 415 anota: "Diferentemente, numa concepção não positivista e não estatista do Direito, o negócio jurídico é entendido como a fonte do regulamento negocial. O negócio, nesta perspectiva, não é puro facto jurídico que, subsumido à norma, desencadeie a conseqüência jurídica. É muito mais: é preceito e é valor. (...) Numa posição mais aberta ao reconhecimento do valor originário da autonomia privada, assume o negócio como vigente numa ampla área de liberdade - a da Autonomia Privada - vigência que não é autorizada pelo ordenamento, mas faz parte dele, e cuja existência é uma exigência da dignidade humana, em Direito Natural."

19 KAUFMANN, Arthur. Filosofia do direito, p. 293 e OLIVEIRA ASCENSÃO. José de. Teoria geral. Ações e fatos jurídicos, pp. 67-70. Para o autor, a autonomia é o fundamento da juridicidade do negócio jurídico e sua causa eficiente. Constitui-se num dos pilares do sistema de direito privado e destina-se a criar efeitos, sendo reconhecida pela ordem jurídica global.

20 OLIVEIRA ASCENSÃO, José de. Teoria geral. Ações e fatos jurídicos, p. 92. De acordo com CARIOTA-FERRARA, “(...) junto a la voluntad y la manifestación, resultam expresados em la definición los limites que derivam, para el império del querer, del princípio de responsabilidad combinado com el de confiança." In: El negocio jurídico, p. 58.

21 KAUFMANN, Arthur. Filosofia do direito, p. 219.

22 CAMARGO, Margarida Maria Lacombe. Hermenêutica e argumentação: uma contribuição ao estudo do direito. 3 ed., revista e atualizada. São Paulo: Renovar, 2003, p.17.

23 LAMEGO, José. Hermenêutica e jurisprudência, p. 71. 
Os preceitos estabelecidos devem ser interpretados em função das razões que os orientam, de acordo com a multiplicidade de realidades existentes e garantindo que o autoregulamento de interesses possa ser respeitado tal e qual pactuado, observados os limites da responsabilidade e confiança que envolvem as partes.

Fixadas essas premissas, passa-se à interpretação dos negócios jurídicos.

\subsection{A interpretação das declarações negociais}

Interpretar consiste em retirar de um texto um determinado sentido ou conteúdo de pensamento.

Conforme anota Costanza ${ }^{24}$, interpretar é individualizar o significado de um ato ou de um fato; é através da interpretação jurídica que se determina a extensão de uma lei, de uma sentença ou de um negócio jurídico. A interpretação jurídica, portanto, visa a determinar qual o conteúdo de uma regulação jurídica ${ }^{25}$.

É a declaração o ponto de partida para a interpretação da manifestação de vontade e, a partir dela, extrair o significado do negócio decorrente da autonomia das partes. As doutrinas clássicas concordavam na proteção da vontade, não obstante apresentarem soluções opostas.

Para a teoria da vontade, o negócio é visto como um ato de liberdade e de vontade do declarante, não valendo sem ou contra essa vontade. A declaração efetuada é um ato de comunicação que revela uma opção que, segundo Larenz $z^{26}$ é um ato de validade, ou seja, um comportamento juridicamente significante. Por outro lado, a teoria da declaração leva em consideração mais o sentido objetivo que dela resulta ou com que

24 COSTANZA, Maria. Profili dell'interpretazione del contrato seconfo buona fede. Milano: Giuffrè Editore, 1989, p. 1.

25 FLUME, Werner. El negocio jurídico. Parte general de derecho civil. Tomo segundo. 4 ed., Madrid: Fundación Cultural del Notariado, 1998, p. 352.

26 LARENZ, Karl. Metodologia da ciência do direito, p. 421. 
o declaratário a entender e pretende, nitidamente, proteger o tráfego jurídico e o seu destinatário.

De acordo com Betti ${ }^{27}$, a unilateralidade dessas orientações interpretativas faz com que se perca de vista o que cada categoria de negócios tem como ponto relevante interpretativo e leva a desconhecer a necessidade de um tratamento diferenciado, conforme a diferente sede que aquele tenha na estrutura típica $^{28}$ do negócio. Como alerta Pais de Vasconcelos, a opção por uma dessas teorias conduzirá a uma concepção objetivista ou subjetivista da interpretação; ambas, porém, “(...) exprimem os modos de ver do subjetivismo e do objetivismo e representam visões dificilmente conciliáveis do negócio jurídico." 29

No Código Civil, o legislador estabeleceu nos artigos $236^{\circ}$ e 237\% uma doutrina geral de interpretação válida para os negócios jurídicos e particularidades no exercício da atividade interpretativa quanto aos negócios formais, conforme se verifica no artigo $238^{\circ}$, que permite alterações no tocante a certas categorias desses negócios.

$\mathrm{O}$ artigo $236^{\circ}$ prevê que a declaração deve ser entendida com "o sentido com que um declaratário normal, colocado na posição de real declaratário, possa deduzir do comportamento do declarante, salvo se este não puder razoavelmente contar com ele." Já o n. 2 do artigo estabelece que "sempre que o declaratário conheça a vontade real do declarante, é de acordo com ela que vale a declaração emitida."

Parte da doutrina portuguesa tem na interpretação dos negócios jurídicos a teoria da impressão do destinatário para a fixação do sentido e alcance das disposições negociais. ${ }^{30}$ Assim,

27 BETTI, Emilio. Teoria geral do negócio jurídico, p. 484.

28 Cfr. KAUFMANN, Arthur. Filosofia do direito, p. 188, o tipo "tem na verdade um núcleo fixo, mas não fronteiras fixas, de tal modo que pode faltar um ou outro dos traços característicos de um tipo sem que seja por isso necessário por em causa a tipicidade de uma determinada situação de fato".

29 VASCONCELOS, Pedro Pais de. Teoria geral do direito civil, p 412.

30 OLIVEIRA, Guilherme de. O testamento: apontamentos, [S.I.]: Reproset, [199?], p. 53; ALARCÃO, Rui de. Interpretação e integração dos negócios jurídicos. Anteprojecto para o novo Código Civil. Separata do Boletim do Ministério da Justiça n. 84. Lisboa, 1959, p. 5. 
teria o legislador optado por uma posição objetivista como regra, exceção feita ao caso de o declaratário ter efetivamente conhecimento da vontade real do declarante, embora ela se afaste do sentido objetivo. Neste caso adotar-se-ia a teoria subjetivista: o sentido que corresponda à real intenção do declarante.

Para o professor Oliveira Ascensão, a vontade manifestada objetivamente ganha por si um significado na vida social, criando uma dialética entre um sentido objetivo e um sentido subjetivo da declaração. Ou seja, na interpretação da declaração negocial em geral há elementos subjetivos relevantes e, "o fato de o art. $236^{\circ}$ acolher a impressão do declaratário não impede que surjam temperamentos subjetivos. Ao ponto de a posição do Código Civil antes dever ser qualificada como mista de objetivismo e subjetivismo." ${ }^{11}$

De acordo com Laren $z^{32}$, a primeira regra de interpretação é: a declaração negocial será interpretada de acordo com a vontade real do declarante sempre que haja consenso. Em havendo concordância quanto ao conteúdo da vinculação, o ato terá o significado que as partes lhe imputaram e, no mesmo norte o professor Pais de Vasconcelos ${ }^{33}$, para quem a segunda regra de interpretação da declaração negocial deve ser o contido no n. 2 do artigo 236 ${ }^{\circ}$ : havendo divergência e o declaratário conheça o sentido subjetivo, deve este prevalecer.

Somente em caso de divergência e desconhecimento pelo declaratário da real intenção do declarante, pode o seu sentido objetivo prevaler desde que não colida com a expectativa razoável do autor da declaração. Essa "expectativa razoável"34 do autor

31 OLIVEIRA ASCENSÃO, José de. A teoria geral do negócio jurídico e o negócio testamentário, p. 37 e no seu Ato e fato jurídico, p. 151.

32 LARENZ, Karl. Metodologia da ciência do direito, p. 422.

33 VASCONCELOS, Pedro Pais de. Teoria geral do direito civil, pp. 550-552. No mesmo sentido, OLIVEIRA ASCENSÃO, José de. Teoria geral do direito civil, p. 313 e COSTA E SILVA, Paula. Acto e processo. O dogma da irrelevância da vontade na interpretação e nos vícios do acto postulativo. Coimbra: Coimbra Editora, 2003, p. 370.

34 Das lições de Maihofer citadas por Pais de Vasconcelos é da Natureza das Coisas que cada pessoa se coloque na posição e no papel do outro, verificando o que nessa perspectiva se poderia razoavelmente esperar e pretender e, assim, exigir de nós próprios. Cfr. VASCONCELOS, Pedro Pais de. A natureza das 
da declaração está relacionada com um critério teleológico-objetivo de interpretação, que visa a determinar e colmatar lacunas ocultas a partir do pensamento tipológico e, por isso, analógico: aquele ir e vir do olhar entre a lei e a concreta situação de fato.

Como ações humanas dotadas de sentido e criadas a partir do poder de auto-regulação das partes, os negócios precisam ser interpretados levando em conta a declaração ou comportamento conforme o conjunto de circunstâncias que lhes confere valor e significado ${ }^{35}$. O intérprete deve estabelecer a correspondência com uma concreta situação da vida, levando em conta a existência de uma realidade multifacetada. Como assevera Betti, "O objeto da interpretação nestes negócios são as declarações permutadas e os comportamentos reciprocamente tidos e reciprocamente reconhecíveis, enquadrados nas circunstâncias concomitantes" ${ }^{\prime 6}$.

Com efeito, a vontade só adquire relevância jurídica na medida em que seja reconhecível sob a forma de declaração ou de comportamento. É o intuito concorde, na sua comum e congruente declaração e conduta, que deve ser interpretada de acordo com o recíproco comportamento das partes, não se afastando a lei dos critérios objetivos quando põe em paralelo o sentido literal das palavras com a intenção comum das partes ${ }^{37}$.

A interpretação da declaração negocial fixa, portanto, o conteúdo e reconstrói o significado das declarações e comportamentos, levando em conta todo o desenrolar das tratativas até a conduta havida após a sua celebração. Nesse sentido, "os cânones hermenêuticos da autonomia e da totalidade" 38 autorizam que o significado do negócio deduza-se também, e especialmente, do comportamento total, do conjunto das declarações ou cláusulas entendidas como um todo.

coisas. In: Estudos em Homenagem ao Professor Dr. Manuel Gomes da Silva. Coimbra: Coimbra Editora, 2001, p. 728 e LARENZ, Karl. Metodologia da ciência do direito, p. 422.

35 BETTI, Emilio. Teoria geral do negocio jurídico, p. 467.

36 BETTI, Emilio. Teoria geral do negocio jurídico, p. 468.

37 BETTI, Emílio. Teoria geral do negócio jurídico, pp. 479-480.

38 BETTI, Emílio. Teoria geral do negócio jurídico, pp. 468. 
A onerosidade ou gratuidade do negócio jurídico também possui influência na interpretação da vontade das partes. $O$ artigo $237^{\circ}$ traz uma regra para os casos em que não se consegue, pela atividade interpretativa, obter um sentido conclusivo e dispõe: "em caso de dúvida sobre o sentido da declaração, prevalece, nos negócios gratuitos, o menos grave para o disponente e, nos onerosos, o que conduzir a um maior equilíbrio das prestações." O problema que se retira do artigo é que nem sempre teremos declarações negociais totalmente gratuitas ou totalmente onerosas, ou seja, nem sempre poderão ser típicas tais declarações.

No plano fático encontramos situações jurídicas intermédias, cuja literalidade da lei não resolverá os questionamentos surgidos de negócios jurídicos atípicos ou menos típicos. A solução parece ser a interpretação de acordo com a equidade, de modo a valorar e ponderar a declaração negocial, a partir das circunstâncias especiais que acompanham o contrato e da sua equação econômica concreta. ${ }^{39}$

Assim, quanto mais onerosa a declaração, mais se aplicam as regras relativas aos negócios onerosos e vice-versa. Consequentemente, "a idéia de direito ou normal legal e a situação da vida devem ser idênticas, para que assim possam ser postas em correspondência recíproca”. Tal correspondência faz com que o intérprete se mova nas zonas cinzentas das transições graduais ${ }^{40}$.

Percebe-se, então, que a idéia de interpretação como concretização de valores e compreensão de sentido admite que, na doutrina da interpretação dos negócios jurídicos, por vezes, “(....) se defendam soluções que não são por inteiro compatibilizáveis com os preceitos legais respectivos." ${ }^{41}$

39 VASCONCELOS, Pedro Pais de. Teoria geral do direito civil, p. 556.

40 KAUFMANN, Arthur. Filosofia do direito, pp. 187-188.

41 LAMEGO, José. Hermenêutica e jurisprudência, p. 67. Nas palavras de Baptista Machado, "Casos há em que a regulamentação jurídica incide sobre instituições básicas, dotadas de uma forte carga afectivo-valorativa e existencial. (...) Nesses casos, o direito tem que respeitar tal realidade, reconhecendo-lhe uma certa autonomia. É então que se diz existir uma "ordem imanente à relação social" que o direito não deve contrariar, assim como é então que o jurista costuma recorrer, na interpretação e integração da lei, à chamada natureza das coisas." In: Introdução ao direito e ao discurso legitimador, p. 29. 
Como é evidente, somente a partir do pensamento tipológico - levando em conta as inúmeras realidades existentes entre o geral e o particular - poderemos encontrar um significado que exteriorize o sentido de correspondência entre realidade e valor.

Assentadas essas posições, ingressa-se no estudo do testamento e seu regramento jurídico.

\section{TESTAMENTO}

\subsection{Considerações prévias}

Historicamente, a autonomia privada está relacionada com o direito patrimonial, com vistas à liberdade de negociar, de escolher o contratante e o conteúdo do contrato e, quando possivel, a forma do ato. Entretanto, apesar de ser utilizada de forma mais restrita, também o é no Direito das Sucessões, por meio do testamento, exteriorização da vontade em que a pessoa dispõe de seus bens para depois da morte ${ }^{42}$.

O testamento é uma das mais antigas formas de manifestação de vontade, sendo importante observar que já no Direito Romano, como lembra Moreira Alves ${ }^{43}$ era levado em consideração que "Testamentum est mentis nostrae iusta contestatio, in id solemniter factum, ut post mortem mostram valente." ${ }^{44}$ Como declaração de vontade, visa a produzir os efeitos jurídicos desejados pelo agente e admitidos pela ordem jurídica, que importam na constituição, na modificação ou na extinção de relações jurídicas.

A declaração de vontade e o cumprimento das formalidades exigidas pela lei tornam válida e perfeita essa manifestação desde o momento de sua outorga pelo testador, sendo a morte a condição que confere eficácia definitiva à manifestação

\footnotetext{
42 AMARAL, Francisco. Direito civil: introdução. 6 ed., Rio de Janeiro: Renovar Editora, 2006, p. 347.

43 MOREIRA ALVES, José Carlos. Direito Romano II. Rio de Janeiro: Forense Editora, 1972 , p. 373.

44 "O testamento é o testemunho justo de nossa mente feito de forma solene para que valha depois de nossa morte." (Ulpiano).
} 
precedente de sua última vontade. Portanto, devidamente realizado, é ato comunicativo da vontade, mas que não vincula o seu autor aos seus sucessíveis, diferentemente dos negócios inter vivos.

A peculiaridade dessa exteriorização traz questionamentos acerca de sua natureza jurídica. A análise da definição legal e de suas características é fundamental para assentarmos as bases que resultarão na melhor interpretação das disposições de última vontade.

\subsection{O testamento como negócio jurídico mortis causa}

O artigo $2179^{\circ}$, n. 1 traz a definição ${ }^{45}$ legal do testamento: "diz-se testamento o acto unilateral e revogável pelo qual uma pessoa dispõe, para depois de sua morte, de todos os seus bens ou de parte deles."

De acordo com o professor Oliveira Ascensão ${ }^{46}$, esta noção é muito semelhante à prevista no artigo 587 do Código Civil italiano. Para o Autor, a expresssão 'de seus bens' exclui outras possibilidades admitidas pelo Direito e sugere o conceito que adotamos para este trabalho: "Testamento é o negócio jurídico unilateral pelo qual alguém procede a disposições de última vontade." 47 Assim, embora não tenha o legislador qualificado o testamento, "a doutrina portuguesa é unânime, salvo erro, em qualificar o testamento como negócio jurídico.”48

45 O legislador optou por definir alguns institutos, não obstante as discussões entre os juristas sobre o problema das definições legais. Para muitos, definir é engessar os institutos e, como nem sempre uma definição jurídica consegue exprimir totalmente a verdade do definido em face da multiplicidade de relações existentes. Portanto, devem ser tidas apenas como norteadoras, não vinculando o intérprete. Cfr. VAZ SERRA, Adriano. A revisão geral do Código Civil. In: BFDUC, XXII, pp. 34-50.

46 OLIVEIRA ASCENSÃO, José de. Direito Civil. Sucessões, pp. 289-290.

47 OLIVEIRA ASCENSÃO, José de. Direito Civil. Sucessões, p. 43.

48 OLIVEIRA ASCENSÃO. José de. A teoria geral do negócio jurídico e o negócio testamentário, p. 33. Na doutrina estrangeira, encontramos autores para quem o fato de a vontade da pessoa desaparecer com a morte traz como consequencia não ser possível falar-se em manifestação de vontade para valer depois da morte, decorrendo o testamento não da autonomia, mas sim, de uma criação do direito. Ainda, para os que discordam da natureza negocial do testamento, o re- 
fenômeno jurídico sucessório se funda na necessidade de tutela a certas situações jurídicas e a possibilidade de testar é consagrar a autonomia privada ${ }^{49}$. Como negócio jurídico por excelência, possui a peculiaridade de ser realizado em vida para produzir efeitos após a morte do declarante.

Diferentemente dos negócios inter vivos que produzem efeitos desde logo, o testamento, como um negócio mortis causa, gerará efeito apenas sobre o fato designativo em si, restando para a abertura da sucessão a produção dos efeitos sobre o conteúdo disposto, conforme artigos $2179^{\circ}, 2031^{\circ}$ e $2050^{\circ}$.

Seguindo essa linha, a natureza causa mortis do testamento impede a aplicação das regras contidas no artigo 224으. n. 1 e 2 que contemplam a teoria da exteriorização, segundo a qual a declaração negocial que não possui um destinatário se torna eficaz desde que o declarante se manifeste na forma adequada. Dessa forma, "cabe, assim, falar apenas no facto de a declaração testamentária se tornar perfeita e válida com a exteriorização na forma legal prescrita, o que não significa que se torne logo eficaz." ${ }^{50}$

Da qualificação ${ }^{51}$ do testamento como negócio jurídico incide a aplicação das regras da teoria geral do negócio jurídico, mas com temperamentos. No caso do testamento, ou se verifica a especificidade testamentária, que afasta a regra geral ou esta se impõe por si; no entanto, a aplicação subsidiária dessas regras

gime jurídico estabelecido na Parte Geral do Código Civil seria aplicável apenas aos negócios inter vivos. CICO, António. Il testamento. Milano: Giuffré Editore, 1942, pp. 3-4 e LIPARI, Nicoló. Autonomia privata e testamento, Milano: Giuffré Editore, 1970, p. 198.

49 LEITÃO. João Sérgio T. de M. Correia. A interpretação do testamento. Lisboa: AAFDL,1991, pp. 57-58.

50 LEITÃO. João Sérgio T. de M. Correia. A interpretação do testamento, p. 68.

51 Conforme ensina o professor Pais de Vasconcelos em sua obra Teoria geral do direito civil, p. 569, após a interpretação, há o intérprete que qualificar o negócio jurídico. Qualificar é relacionar e comparar o preceito normativo (subjetivo) e o ordenamento legal (objetivo), implicando "num movimento espiral e hermenêutico, assente numa pré-compreensão que se traduz em pré-qualificações experimentais precarias feitas com apoio na cultura jurídica e na experiência do mundo de quem qualifica." 
precisa ser realizada de forma valorativa, balizando-se o que é ou não passível de ser generalizado ${ }^{52}$.

Com efeito, haverá sempre a possibilidade de o intérprete recorrer subsidiariamente à parte geral quando as disposições específicas $\left(2187^{\circ}\right.$ n.1 e 2) não oferecerem resposta adequada a questões de hermenêutica, posto que "a teoria geral constitui um regime geral, em condições de ser diretamente aplicado em todo o sector de que não for especificamente afastada." ${ }^{53}$

Conclui-se, assim, pela natureza negocial do testamento e pela possibilidade de aplicação subsidiária das regras relativas à parte geral para a sua interpretação. $\mathrm{O}$ que caracteriza e fundamenta o testamento é exclusivamente a autonomia do testador, que outorga proteção especial ao beneficiário, não existindo “(...) protecção sucessória nenhuma que se contraponha à vontade do testador, porque só é chamado àquela sucessão por obra e graça da vontade do testador, justamente. ${ }^{54}$

Desse enquadramento jurídico decorrem significativas consequências para a interpretação do testamento, objeto central deste trabalho. Segue-se destacando as suas características e os vários aspectos que envolvem a liberdade de testar.

\subsection{O testamento como facto designativo: características e conteúdo}

De acordo com o professor Oliveira Ascensão, designação "é o ato intelectual pela qual se determinam os sucessíveis de alguém. Dela resulta para algumas pessoas a atribuição da qualidade de sucessível." ${ }^{55}$

52 OLIVEIRA ASCENSÃO, José de. Teoria geral do negócio jurídico e o negócio testamentário, p. 35; LEITÃO. João Sérgio T. de M. Correia. A interpretação do testamento, p. 58 e CARVALHO FERNANDES, Luís A. Interpretação do testamento. In: Estudos em homenagem ao Professor Doutor Inocêncio Galvão Telles: 90 anos. Homenagem da Faculdade de Direito de Lisboa. Coimbra: Almedina Editora, 2007, p. 720.

53 OLIVEIRA ASCENSÃO, José de. Teoria geral do negócio jurídico e o negócio testamentário, p. 35.

54 OLIVEIRA ASCENSÃO, José de. Teoria geral do negócio jurídico e o negócio testamentário, p. 35.

55 OLIVEIRAASCENSAO, José de. Direito civil. Sucessões, p. 57. 
Quando alguém é contemplado em testamento, passa a ter uma expectativa sucessória que, por lei, se perfectibilizará com a morte do testador e com a respectiva aceitação da herança ou legado. No entanto, existem disposições que possuem efeito retroativo: "enquanto a generalidade das disposições se destinam a produzir efeito depois da morte, outras, como o reconhecimento de uma dívida ou a perfilhação são retroactivas, sendo só dadas a conhecer com a abertura da sucessão". ${ }^{56}$

Com efeito, é o testamento um negócio jurídico personalíssimo, que carrega em sua estrutura jurídica características de ser pessoal, unilateral, solene, gratuito e revogável.

Como ato personalíssimo (artigos $2182^{\circ}$ e $2184^{\circ}$ ), o testamento só pode ser realizado pelo autor da herança, que deve exprimir integralmente a sua vontade. $\mathrm{O}$ sistema legal exige que todas as disposições sejam tomadas pelo próprio testador, não sendo possivel fazer um testamento por procuração, nem fazer testamento para outrem, sendo que a legislação, no máximo, admite que o testador possa ser auxiliado, no aclaramento de sua vontade e compreensão dos respectivos efeitos, por alguém de sua confiança ou um profissional da área jurídica. Trata-se do princípio da pessoalidade que abrange dois aspectos e por ele se exclui: 1 . a atuação de representante na feitura do testamento; 2. A remessa ao arbítrio de outrem quer da fixação do seu conteúdo, quer da sua execução. ${ }^{57}$

Outra característica importante é a sua unilateralidade. $\mathrm{O}$ testamento reúne um único centro de interesses e, na medida em que seu autor é uma só pessoa, diz-se que possui caráter singular. O artigo $2181^{\circ}$ estabelece: "não podem testar no mesmo acto duas ou mais pessoas, quer em proveito recíproco, quer em favor de terceiro".

O caráter não recipiendo (ou não receptício) do testamento liga-se ao fato de que a eficácia das suas disposições não depende do conhecimento dos beneficiários ou de outrem e, portanto,

56 OLIVEIRA ASCENSÃO, José de. Direito civil. Sucessões, p. 293. 57 OLIVEIRA ASCENSÃO, José de. Direito civil. Sucessões, pp. 48-49. 
não existindo um declaratário do testamento, o fenômeno sucessório ocorre independentemente desse conhecimento. Assim, só a vontade pessoalmente manifestada pelo testador é suficiente à formação do testamento, não necessitando o beneficiário de intervir para a sua perfeição e validade. ${ }^{58}$

Possui ainda a característica de ser gratuito, por decorrer de uma liberalidade que contém atribuições patrimoniais ${ }^{59}$, sem o respectivo sacrifício por parte do beneficiário.

A forma exigida pelo legislador é a solene ${ }^{60}$, com vistas a garantir a autenticidade e a espontaneidade das declarações de última vontade, pressupostos de validade do testamento. Este é, por essência, revogável (art. 2179) somente por outro testamento e, até a sua morte, o testador a qualquer momento poderá torná-lo ineficaz, ou parte dele, tendo autonomia total e podendo assim proceder enquanto vivo e capaz.

O testamento contém disposições de última vontade destinadas a regular a devolução dos bens hereditários e é nas disposições de ordem patrimonial, que se concentra geralmente o conteúdo do testamento. No entanto, a lei possibilita que seu conteúdo seja apenas extrapatrimonial (artigo 2179, n. 2), de modo que é vedado ao notário recusar-se a lavrar um testamento apenas com disposições desta ordem.

O que essa conformação apresenta de peculiar é a possibilidade de se distinguir no testamento um conteúdo típico (ato de atribuição patrimonial) e outro atípico (impossível de definir em abstrato o seu conteúdo, podendo ser ele patrimonial ou extrapatrimonial). Daí porque, para Menezes Cordeiro, o testamento é um negócio "totalmente atípico uma vez que, por seu

58 OLIVEIRA ASCENSÃO, José de. Direito civil. Sucessões, p. 72.

59 Conforme GALVÃO TELLES, "atribuição patrimonial é toda a vantagem avaliável em dinheiro". In: Manual dos contratos em geral, 3 ed. Reimpressão da 3 ed. de 1965. Lisboa: Lex, 1995, p. 400.

60 Adotamos a linha de pensamento dos professores MENEZES CORDEIRO e OLIVEIRA ASCENSÃO, segundo os quais a melhor designação para os negócios cuja lei exija forma especial é negócio solene e não negócio formal. Isso porque todo o negócio tem uma forma, de modo a ser cognoscível. O que se exige nos negócios formais ou solenes é uma forma especial, um certo tipo de comportamento declarativo, cuja inobservância o torna nulo (artigos $220^{\circ}$ e $2026^{\circ}$, n. 5). 
intermédio pode ser conseguido um número indeterminado de efeitos." 61

Nesse sentido, o conteúdo de um testamento pode comportar múltiplos sentidos e com freqüência encontramos palavras obscuras ou ambíguas, que acarretam dificuldades na compreensão do ato comunicativo de última vontade do disponente. Inúmeras são as situações em que surgem dificuldades de interpretação que seriam, inicialmente, insuspeitadas e imprevisíveis. ${ }^{62}$

Como bem anota Betti ${ }^{63}$, "O reconhecimento do sentido da disposição testamentária com o auxílio da "mens testantis", mais que com o da "figura verborum" constitui um problema hermenêutico essencialmente diferente do reconhecimento do preceito contratual com a ajuda da comum intenção prática das partes, e não apenas com a do sentido literal das palavras."

Em sede de testamento o ponto de relevância hermenêutica $^{64}$ encontra-se na figura do declarante, cuja declaração cria uma relação necessária entre quem morre e o seu sucessor, exigindo tratamento hermenêutico diferenciado das declarações negociais inter vivos, como se verá adiante.

\section{A INTERPRETAÇÃO DO NEGÓCIO TESTAMENTÁRIO}

\subsection{Considerações iniciais}

A interpretação dos testamentos se insere na doutrina geral da interpretação, encontrando paralelo com a interpretação dos contratos e a própria interpretação das leis. Lembra

61 MENEZES CORDEIRO, António. Direito das Obrigações.V. 1, Lisboa : AAFDL, 1994, p. 562.

62 BAPTISTA MACHADO, João. Introdução ao direito e ao discurso legitimador, p. 175.

63 BETTI, Emílio. Teoria geral do negócio jurídico, pp. 473-474.

64 "Há, portanto, um ponto relevante para o tratamento interpretativo - ponto de relevância hermenêutica -que o jurista intérprete deve procurar numa sede, que é diferente conforme a estrutura exigida para a eficácia jurídica do negócio." Cfr. BETTI, Emílio. Teoria geral do negócio jurídico, p. 471. 
Costa e Silva ${ }^{65}$ que "tanto na interpretação do testamento como na interpretação da declaração negocial aquilo a que se procura reconstituir é a intenção do declarante."

No testamento só importa que se cumpra a vontade declarada ${ }^{66}$, sem atenção às expectativas dos beneficiários. Tal peculiaridade traz um afastamento inicial das regras do regime contido no artigo $236^{\circ}$ e, em particular, ao regime especial de interpretação do negócio solene fixado no artigo 238 .

Partindo dessa premissa, é importante notar que a interpretação dos negócios testamentários apresenta um problema essencialmente diferente da interpretação dos negócios inter vivos, em especial dos contratos.

Nos negócios jurídicos inter vivos o intérprete encontra pela frente duas partes e seu objetivo é compor os interesses entre declarante e declaratário. Já nos testamentos, o intérprete, embora tenha como pressuposto as declarações do testador, não encontra qualquer conflito entre os sujeitos da relação: por um lado tem-se o de cuius e, por outro, herdeiros e legatários.

No testamento a vontade é única e o intérprete não necessita amoldar-se a qualquer interesse oposto. Então podemos afirmar que, "se existe diferença entre a interpretação do testamento e a interpretação da declaração em geral, esta diferença reside essencialmente na desconsideração da situação jurídica daqueles que actuam na sequência do testamento." ${ }^{\prime 7}$

Um dos grandes problemas da interpretação do negócio testamentário está na elucidação das declarações efetuadas no testamento e seu contexto, em face da ausência do testador para atribuir o real significado da exteriorização de seu querer e de regras próprias para a sua interpretação. Anota Costa e Silva ${ }^{68}$ que, o que é absolutamente característico da interpretação de um acto mortis causa é a impossibilidade de ele ser interpretado autenticamente pelo seu autor.

65 COSTA E SILVA, Paula. Acto e processo, p. 420.

66 FLUME, Werner. El negocio jurídico, p. 397.

67 COSTA E SILVA, Paula. Acto e processo, p. 421.

68 COSTA E SILVA, Paula. Acto e processo, p. 418. 
Como negócio solene, a redução da vontade do testador a um documento escrito fazem de sua letra o elemento mais relevante da interpretação e, a doutrina e jurisprudência ${ }^{69}$ há muito trabalham na perspectiva de encontrar um caminho para atender a real intenção do testador, exteriorizada através de enunciados lingüísticos (constituídos por palavras, atos ou condutas não verbalizados) e não o significado objetivo do testamento. ${ }^{70}$

Levando-se em conta que na interpretação das ações humanas há "uma componente significativa, que tem de ser reconhecida como tal por um sujeito e transportada para o seu próprio sistema de valores e significados," ${ }^{11}$ grande é o desafio de tornar objetivas as descrições de sentido subjetivamente intencionais, uma vez que passam pela subjetividade do próprio intérprete.

Então, como encontrar o real ou provável sentido da declaração de vontade emitida pelo testador? Concretizando: em face da morte da mãe (beneficiária) antes da testadora e em circunstância em que não se discute 'morte simultânea' com esta, se mantém válida e em vigor a cláusula que beneficia os primos? E, em caso afirmativo, esta deixa testamentária corresponderá à totalidade da herança ou apenas a quota disponível?

\subsection{A interpretação da vontade do testador e o recurso à prova complementar}

Conforme visto, à interpretação das disposições testamentárias são aplicáveis princípios distintos dos que orientam a interpretação dos contratos, não obstante a possibilidade de recurso subsidiário às regras constantes da parte geral a partir de seu controle valorativo.

69 Conforme acórdãos do Supremo Tribunal de Justiça: n. 200301300044487, de 30.01.2003; n. 20080923021256, de 23.9.2008; 20080422007846, de 22.4.2008 e 20070313046561, de 13.6.2007. Disponível em www.dgsi.pt. Acesso em 04.05.2012.

70 LEITÃO. João Sérgio T. de M. Correia. A interpretação do testamento, p. 78.

71 BLEICHER, Josef. Hermenêutica contemporânea. Lisboa: Edições 70 Editora, 1998, p. 13. 
O Código Civil estabelece preceitos específicos sobre a matéria e possui como regra fundamental o disposto no artigo 2187, n. 1: "Na interpretação das disposições testamentárias observar-se-á o que parecer mais ajustado com a vontade do testador, conforme o contexto do testamento." Essa regra traz a principal meta da interpretação dos testamentos: esclarecer o pensamento do disponente ainda que não se encontre exprimido de maneira adequada na declaração, "mas que resulte de circustâncias exteriormente reconhecíveis, no círculo social do disponente, mercê de ilações tiradas da experiência comum." ${ }^{\prime 2}$

A lei consagrou o princípio hermenêutico da totalidade e o intérprete, a partir de uma interpretação tendencialmente individual, deve procurar nas expressões e no comportamento do testador o significado mais em conformidade com a sua maneira pessoal de ser e estar no mundo, atentando-se para o contexto do testamento e, em última análise, do apresentado ao redor do pensamento exteriorizado através da declaração. Portanto, a declaração negocial testamentária deve ser interpretada a partir de uma ótica subjetivista ${ }^{73}$, cujo fundamento deve ser procurado no próprio conceito de negócio jurídico ${ }^{74}$.

72 BETTI, Emilio. Teoria geral do negócio jurídico, p. 514.

73 Há quem entenda residir no fato de haver uma vantagem patrimonial para alguém sem o respectivo sacrifício (gratuidade) o fundamento para a diretiva subjetivista. Há ainda teóricos que defendem que a interpretação subjetiva deve prevalecer em face do caráter unilateral não receptício do testamento, posto não haver declaratário com interesse a ser poderado e, portanto, nenhum relevo de um princípio da confiança, que só funcionaria nos negócios recipiendos. Por outro lado, há quem admita a subjetividade na interpretação do testamento em face deste ser apenas um meio de conhecimento que não vincula os beneficiários devendo valer de acordo com a real vontade do testador. Ainda, a interpretação subjetivista se justificaria posto ser a única forma de respeitar a vontade do testador. Este é o argumento de Ferrer Correia em sua obra 'Erro e intepretação do negócio jurídico'. Anote-se também a posição do professor Antunes Varela em sua 'Inefícácia do testamento e a vontade conjectural do testador', que considera que a origem desta interpretação está no fato de a preferência do beneficiário real (apoiado na vontade real do testador) da disposição testamentária sobre o beneficiário aparente (fundado no sentido objetivamente reconhecível da cláusula). Por fim, há ainda o posicionamento baseado no conceito de "negócio estranho ao comércio jurídico." Tudo conforme informa LEITÃO. João Sérgio T. de M. Correia. A interpretação do testamento, pp. 111-123.

74 LEITÃO. João Sérgio T. de M. Correia. A interpretação do testamento, p. 123. Em sentido contrário, entende COSTA E SILVA, ao afirmar que "O fundamento para a desprotecção do declaratário na interpretação do testamento não pode, assim, 
Como ato da autonomia privada, o testamento não necessita amoldar-se a qualquer interesse oposto e, por isso, é lógico que o sentido da declaração deve corresponder ao pensamento do disponente, ressalvado o limite atinente à sua forma, haja vista o seu caráter solene. Aliás, "a fundamentação para a aplicação exclusiva da orientação subjetivista terá que encontrar-se no facto de não revelar aqui qualquer tutela da confiança." ${ }^{75}$

Nesse mesmo sentido é o pensamento de Betti ${ }^{76}$, para quem a teoria da vontade se mostra razoável como orientação interpretativa para aqueles negócios em que não haja um conflito de interesses, "em que desaparece a necessidade de tutelar a expectativa gerada, de acordo com a boa-fé, em quem está autorizado a depositar confiança na declaração alheia, e não entram em jogo as necessidades do comércio e da circulação”.

Com efeito, a letra do testamento é relevante na interpretação, constituindo-se, num primeiro momento, no limite ao apuramento de seu sentido subjetivo ${ }^{77}$. Contudo, o seu contexto exerce influência na medida em que o conjunto das cláusulas testamentárias refletem o ambiente circunstancial em que tais disposições foram concretizadas. As palavras são o ponto de partida, mas não possuem valor decisivo para a descoberta da intenção do de cuius.

Para auxiliar neste trabalho é possível buscar-se fora do testamento elementos úteis à sua interpretação ${ }^{78}$. $\mathrm{O}$ ordena-

fazer-se decorrer de características estruturais do acto, mas de uma opção do legislador. Quis a lei, no caso do testamento, fazer prevalecer a vontade do de cuius sobre qualquer outro interesse. Pode tê-lo feito atendendo a um 'imperativo civilizacional."' In: Acto e processo, pp 421-422, nota 965.

75 LEITÃO. João Sérgio T. de M. Correia. A interpretação do testamento, p. 128; OLIVEIRA ASCENSÃO, José de. A teoria geral do negócio jurídico e o negócio testamentário, pp.37-38 e PALAZZO, Antonio. Testamento e istituti alternativi. Grandi questioni e pareri. Pádova: CEDAM Editore, 2008, pp. 13-14.

76 BETTI, Emilio. Teoria geral do negocio jurídico, p. 482.

77 CARVALHO FERNANDES, Luís A. Interpretação do testamento, pp. 734-735.

78 O professor CASTRO MENDES defende que, no caso de o contexto do testamento impor uma só solução, vale a corrente objetivista da interpretação, afastandose o recurso à prova complementar. Apenas no caso de a disposição testamentária comportar várias interpretações é que se poderia buscar fora do testamento soluções para a obscuridade. Cfr. CASTRO MENDES, João de. Interpretação de testamento: prova complementar, competência do Supremo tribunal de Justiça. 
mento jurídico permite utilizar dados estranhos ao seu texto, que possam ajudar a descobrir o sentido verdadeiro de expressões controvertidas, admitindo a consulta às circunstâncias da causa, ainda que extrínsecas.

O testamento deve ser interpretado por si mesmo; mas se contém fatos ou implica circustâncias que sejam objeto de controvérsias, autoriza o legislador o recurso às provas extrínsecas. Assim, embora a positividade signifique segurança jurídica $^{79}$, o Código Civil estabelece no artigo 2187\%, n. 2 que "É admitida prova complementar, mas não surtirá qualquer efeito a vontade do testador que não tenha no contexto do testamento um mínimo de correspondência, ainda que imperfeitamente expressa”.

Com efeito, a expressão "um mínimo de correspondência, ainda que imperfeitamente expressa” é conceito indeterminado com conteúdo e extensão incertos e cujo preenchimento ocorrerá apenas com a valoração no caso concreto. ${ }^{80}$

Lembra Baptista Machado ${ }^{81}$ que os conceitos indeterminados e as cláusulas gerais ${ }^{82}$, constituem "a parte movediça e

In: R.D.E.S., ano XXIV, n. 1-2-3-, Jan./Set., 1977, p. 108. Ao contrário, "a actividade judicial de interpretação negocial depende, não da obscuridade da declaração, mas do aparecimento de um litígio de interpretação," concluindo que a regra do art. $2187^{\circ}$ n. 1 e n. 2 são sempre de se aplicar. Cfr. LEITÃO. João Sérgio T. de M. Correia. A interpretação do testamento, p. 102 e CARVALHO FERNANDES, Luís A. Interpretação do testamento, p. 738.

79 KAUFMANN, Arthur. Filosofia do Direito, p. 184. O autor afirma que, por causa da função operativa (segurança jurídica) da linguagem legal, esta deveria ser o mais possível exata, unívoca. Porém, as normas apenas se tornam efetivas se forem abertas às situações da vida e em nenhum juízo de realidade encontramos o conceito unívoco.

80 LEITÃO. João Sérgio T. de M. Correia. A interpretação do testamento, p. 104.

81 BAPTISTA MACHADO, João. Introdução ao direito e ao discurso legitimador, pp. 113.

82 De acordo com o professor BAPTISTA MACHADO, "A cláusula geral contrapõe-se, pois, à regulamentação casuística ou tipificada. Característico da cláusula geral é a sua maior abertura, que alarga o seu campo de aplicação, deixando bastante indefinidos os casos a que virá a aplicar-se. In: Introdução ao direito e ao discurso legitimador, p. 114. Ainda, a contribuição de ENGISCH, para quem o "verdadeiro significado das cláusulas gerais reside no domínio da técnica legislativa. Graças à sua generalidade, elas tornam possível sujeitar um ou mais vasto grupo de situações, de modo a ilacunar e com possibilidade de ajustamento, a uma conseqüência jurídica" In: Introdução ao pensamento jurídico, 10 ed. Lisboa: Fundação Calouste Gulbenkian, 2008, p. 234. 
absorvente do ordenamento jurídico", cuja função é “(...) ajustar e fazer evoluir a lei no sentido de a levar ao encontro das mudanças e das particularidades das situações da vida".

Como o ponto de relevância hermenêutica do testamento reside na declaração emitida pelo testador, o legislador, em atenção à importância da realidade material subjacente tomou o cuidado de possibilitar que o intérprete pudesse, na concretização do pensamento do testador, levar em conta as circunstâncias individuais do caso apresentado.

É possível, assim, a compatibilização entre os termos do testamento (prova intrínseca) com outros elementos ou circunstâncias (extrínsecas, complementares, extratestamentárias) que possam auxiliar na determinação da vontade do testador, desde que haja fundadas razões para se duvidar de sua intenção. ${ }^{83}$

A interpretação do testamento deve estar em conformidade com o seu contexto formal. No caso, é especial averiguar se a declaração do testador, enquadrada no conjunto de circunstâncias que lhe conferem valor e significado possui, como exige o n. 2 do artigo $2187^{\circ}$, um mínimo de apoio no texto do documento.

Infere-se da lógica do sistema ${ }^{84}$ que, dentre os vários sentidos que a disposição ambígua pode ser entendida, é preferível aquela que, segundo as regras de experiência e tendo em conta as opiniões pessoais do testador, "possa deduzir-se de indícios atendíveis, recolhidos do seu círculo social" ${ }^{85}$.

A testadora deixou a parte disponível para a mãe, prevendo expressamente que, em 'caso de morte simultânea delas' ou 'em caso de dúvida', esses bens fossem entregues aos primos da linha materna.

83 ANTUNES VARELA, João de Matos. Ineficácia do testamento e a vontade conjectural do testador. Coimbra: Coimbra Editora, 1950, pp. 24 e ss.

84 "O papel do conceito de sistema é o de traduzir e realizar a adequação valorativa e a unidade interior da ordem jurídica." Cfr. CANARIS, Claus-Wilhelm. Pensamento sistemático e conceito de sistema na ciência do direito. Introdução e tradução de A. Menezes Cordeiro. Lisboa: Fundação Calouste Gulbenkian Editora, 1989 , p. 23.

85 BETTI, Emilio. Teoria geral do negócio jurídico, p. 493. 
Não obstante ser a interpretação gramatical, num primeiro momento, a forma de o intérprete compreender a disposição testamentária, o artigo $2187^{\circ}$, n. 1 é claro ao prever que na interpretação das disposições testamentárias deve-se observar o que parecer mais ajustado com o pensamento do testador.

Ora, da literalidade cotejada com o contexto do testamento, verifica-se que a intenção da testadora foi a de beneficiar sua mãe com a quota disponível, resguardando ainda a estirpe materna, na medida em que expressamente designou os primos desta linhagem como substitutos no caso de ausência da mãe.

Some-se a isso o fato de a testadora, mesmo com a morte dos genitores, não ter modificado os parâmetros do testamento para beneficiar sua irmã unilateral consanguínea, a fim de que esta recebesse toda a herança. A testadora estava satisfeita com os efeitos que desencadearia a disposição efetuada.

Do contexto do testamento retiramos que a presumível vontade da testadora era deixar a parte disponível, em caso de impossibilidade da mãe recebê-la, aos primos da linha materna, com quem tinha mais contato em vida. Reforça essa conclusão o fato de, no documento, ter a disponente entrelinhado as expressões que se referiam à idéia da transmissão de seus bens aos primos.

Com Betti, entendemos que esta interpretação assim deve ser por força da forma essencialmente individual com que o intérprete deve realizá-la, procurando nas expressões e nos comportamentos o significado mais conforme a maneira pessoal de ver do disponente, tal como ela resulta da sua cultura e de seus hábitos ${ }^{86}$. As expressões utilizadas no testamento devem ser intepretadas "(...) naturaliter e não civiliter, isto é, não no significado técnico-jurídico, mas naquele que presumivelmente as palavras escolhidas tinham em sua mente." 87

86 BETTI, Emilio. Teoria geral do negócio jurídico, p. 514.

87 GOMES, Orlando. Sucessões. 13 ed. Revista, atualizada e aumentada de acordo com o Código Civil de 2002 por Mário Roberto Carvalho de Faria. Rio de Janeiro: Forense Editora, 2006, p. 149. 
O intérprete deve imaginar-se na posição do testador, colocando-se em seu lugar ao testar, a fim de penetrar em seu íntimo e dar o devido peso a seus hábitos. Assim, "o intérprete pode socorrer-se de todo o circunstancialismo anterior ou posterior à feitura do testamento que lhe permita concluir qual a vontade real do testador." 88

Nessa linha de raciocínio, no caso parâmetro utilizado para a pesquisa, podemos aferir que a testadora estava satisfeita com o fato de a irmã receber somente a parte correspondente à legítima, caso contrário teria modificado a disposição testamentária.

Como anota Guimarães ${ }^{89}$, "a conduta do testador após o testamento pode explicitar a sua declaração anterior, mas valerá só como meio de interpretação da vontade fixada no texto (...)." Portanto, a cláusula que beneficia os primos com a parte disponível deve ser considerada válida, haja vista retirar-se da intrínseca coerência e totalidade do negócio testamentário a intenção da disponente nesse sentido. À irmã consanguínea cabe apenas a parte referente à legítima.

É através do pensamento tipológico que todo o Direito deve ser pensado e é apenas colocando-se na posição e no papel da outra parte na relação típica da vida, que o intérprete deve interrogar-se sobre o que, nessa perspectiva, poderia o declarante razoavelmente esperar e pretender.

\section{CONCLUSÃO}

O estudo realizado permitiu-nos verificar que o centro de gravidade do sistema jurídico está na vontade, fundamento da autonomia privada e corolário do Estado de Direito, na medida em que permite aos particulares a autoregulação da vontade com fins na realidade exterior.

88 LEITÃO. João Sérgio T. de M. Correia. A interpretação do testamento, pp.97-98. 89 GUIMARÃES, Maria de Nazareth Lobato. Testamento e autonomia (algumas notas críticas, a propósito de um livro de Lipari) In: R.D.E.S., ano XVIII, n. 1-2-3-4. Jan./Dez. 1971, p. 79. 
Como declaração negocial, o testamento reflete o sentido atribuído pelo testador ao tempo da elaboração e aprovação do texto e não necessita amoldar-se a qualquer interesse oposto, seja de destinatários ou do tráfego jurídico. Diferentemente das regras gerais que regem a interpretação do negócio jurídico $\left(236^{\circ}\right.$ a $\left.238^{\circ}\right)$, na interpretação do testamento não há a nenhum outro interesse a ser preservado que não o do testador.

Dessa forma, o conteúdo qualitativo da complexa posição jurídica em que o sucessível fica investido após a aceitação é determinado pela vontade do de cuius, cabendo apenas ao ordenamento jurídico reconhecer aquela manifestação de vontade e conceder-lhe efeitos. Como operação intelectual que visa à concretização de valores e a compreensão do sentido da declaração efetuada, a interpretação do testamento revela-se como ponto fundamental do Direito Sucessório, na medida em que permitirá que a manifestação de vontade do falecido seja atendida.

No entanto, as dificuldades aparecem quando da produção dos efeitos da declaração negocial testamentária, ou seja, da abertura da sucessão, posto que o testador não estará presente para explicitar a sua vontade em caso de dúvida acerca das disposições. O intérprete necessitará verificar a globalidade das circunstâncias existentes anteriormente e na abertura da sucessão, juntamente com o texto afirmado, a fim de concretizar o mais fielmente possível a vontade do de cuius.

Muito embora a qualificação do testamento como "negócio jurídico", sua interpretação é de cariz subjetivista e deve o intérprete ter especial atenção para as particularidades próprias de sua natureza jurídica: ser uma declaração de vontade unilateral não receptícia, com eficácia mortis causa, que autoriza ter em conta o entendimento concreto do disponente, ainda que divergente do significado comum das palavras por ele utilizadas, em atenção ao artigo $2187^{\circ}$.

A vontade do testador só não pode valer se não tiver no conjunto da expressão do testamento um mínimo de correspon- 
dência, ainda que imperfeitamente expresso. ${ }^{90}$ Assim, quando confrontado com disposição que comporte a possibilidade de valer com mais que um sentido, impõe-se ao intérprete a tarefa de averiguar com recurso a todos os meios disponíveis o efetivo pensamento do testador.

No caso paradigma utilizado para o desenvolvimento da investigação, percebeu-se do contexto da declaração negocial testamentária que, dada a situação fática existente no momento da abertura da sucessão, intencionava a de cuius beneficiar os primos com a parte disponível de seu patrimônio; caso contrário teria alterado o ato comunicativo de sua manifestação de vontade após o falecimento dos genitores em favor da irmã. Posto isto, resta concluir que a interpretação subjetivista do testamento é o norte para considerar-se válida e em pleno vigor a cláusula que beneficia os primos, não obstante a morte da mãe em momento anterior à testadora.

Abstract: The will is a designative fact by which the testator, by reason of their autonomy, designates their successors from a statement with a patrimonial or extra patrimonial content, which will take effect after his death. Its effect has its cause in the death of the author, which is why the moment of its realization and the time of the opening of succession are of great importance for the verification of legal values underlying the will, and the determination of the meaning and scope corresponding to the real intent of the Disposer. The present study aims to contribute to the discussions concerning conditions in the interpretation of wills, specially, to clarify the volitional content of the de cujus declaration, in order to determine the effects that will be produced taking into consideration the purpose desired by the author.

Keywords: Interpretation of wills. Testamentary Legal Business. Wills.

90 FLUME, Werner. El negocio jurídico, p. 399. Também CARVALHO FERNANDES, Luís A. Interpretação do testamento, p. 732 e COSTA E SILVA, Paula. Acto e processo, p. 419. 


\section{REFERÊNCIAS}

ABREU FILHO, José. O negócio jurídico e sua teoria geral. 5 ed., São Paulo: Saraiva Editora, 2003.

ALARCÃO, Rui de. Interpretação e integração dos negócios jurídicos.

Anteprojecto para o novo Código Civil. In: Separata do Boletim do Ministério da Justiça n. 84. Lisboa, 1959.

AMARAL, Francisco. Direito civil: introdução. 6 ed., Rio de Janeiro: Renovar Editora, 2006.

ANDRADE, Manuel da Costa. Teoria geral da relação jurídica. V. 2.

Coimbra: Almedina Editora, 1972.

ANTUNES VARELA, João de Matos. Ineficácia do testamento e a vontade conjectural do testador. Coimbra: Coimbra Editora, 1950.

BAPTISTA MACHADO, João. Introdução ao direito e ao discurso legitimador. 18 reimpressão. Coimbra: Almedina Editora, 2000.

BETTI, Emilio. Teoria geral do negócio jurídico. Campinas: Servanda Editora, 2008.

BLEICHER, Josef. Hermenêutica contemporânea. Lisboa: Edições 70 Editora, 1998.

CAMARGO, Margarida Maria Lacombe. Hermenêutica e argumentação: uma contribuição ao estudo do direito. 3 ed., revista e atualizada. São Paulo: Renovar, 2003.

CANARIS, Claus-Wilhelm. Pensamento sistemático e conceito de sistema na ciência do direito. Introdução e tradução de A. Menezes Cordeiro. Lisboa: Fundação Calouste Gulbenkian Editora, 1989.

CARIOTA-FERRARA, Luigi. El negocio jurídico. Trad. del italiano, prólogo y notas de Manuel Albaladejo. Madrid: Aguilar, 1956.

CARVALHO FERNANDES, Luís A. Interpretação do testamento. In: Estudos em homenagem ao Professor Doutor Inocêncio Galvão Telles: 90 anos. Homenagem da Faculdade de Direito de Lisboa. Coimbra: Almedina Editora, 2007.

CASTRO MENDES, João de. Interpretação de testamento: prova complementar, competência do Supremo Tribunal de Justiça. In: R.D.E.S., 
ano XXIV, n. 1-2-3-, Jan./Set., 1977.

CICO, António. Il testamento. Milano: Giuffré Editora, 1942.

COSTANZA, Maria. Profili dell'interpretazione del contrato seconfo buona fede. Milano: Giuffrè Editore, 1989.

COSTA E SILVA, Paula. Acto e processo. O dogma da irrelevância da vontade na interpretação e nos vícios do acto postulativo. Coimbra: Coimbra Editora, 2003.

ESTEVES, Jorge Manuel A. De Almeida. Os limites da interpretação jurídica e a responsabilidade do intérprete. In: Revista Jurídica da Universidade Portucalense, n. 14. Porto, 2010, p. 127.

ENGISCH, Karl. Introdução ao pensamento juridico. 10 ed. Lisboa: Fundação Calouste Gulbenkian, 2008.

FERRER CORREIA, António. Erro e interpretação na teoria do negócio jurídico. 2 ed., Coimbra: Almedina Editora, 1985.

FERRI, Giovanni. Il negozio giuridico. Padova: CEDAM Editora, 2001.

FLUME, Werner. El negocio juridico. Parte general de derecho civil. Tomo segundo. 4 ed., Madrid: Fundación Cultural del Notariado, 1998.

GALVÃO TELLES, Inocêncio. Teoria geral do fenômeno sucessório, Lisboa, 1944. . Manual dos contratos em geral. 3 ed., Lisboa: Lex,

GOMES, Orlando. Sucessões. 13 ed. Revista, atualizada e aumentada de acordo com o Código Civil de 2002 por Mário Roberto Carvalho de Faria. Rio de Janeiro: Forense Editora, 2006.

GUIMARÃES, Maria de Nazareth Lobato. Testamento e autonomia (algumas notas críticas, a propósito de um livro de Lipari). In: R.D.E.S., ano XVIII, n. 1-2-3-4. Jan./Dez. 1971.

KAUFMANN, Arthur. Filosofia do direito. 4 ed. Lisboa: Fundação Calouste Gulbenkian Editora, 2010.

LAMEGO, José. Hermenêutica e jurisprudência. Análise de uma recepção. Lisboa: Fragmentos Editora, 1990.

LARENZ, Karl. Metodologia da ciência do direito. 3 ed., tradução de José Lamego. Lisboa: Fundação Calouste Gulbenkian Editora, 1997. 
LIPARI, Nicoló. Autonomia privata e testamento. Milano: Giuffré Editore, 1970.

MENEZES CORDEIRO, António. Direito das Obrigações. V. 1.

Lisboa: AAFDL, 1994.

LEITÃO. João Sérgio T. de M. Correia. A interpretação do testamento. Lisboa: AAFDL,1991.

MOREIRA ALVES, José Carlos. Direito Romano II. Rio de Janeiro: Forense Editora, 1972.

OLIVEIRA ASCENSÃO, José de. Teoria geral do negócio jurídico e o negócio testamentário. In: Revista da Faculdade de Direito da Universidade de Lisboa. Coimbra: Coimbra Editora, 2003.

Editora, 2010.

. Teoria geral. Ações e fatos jurídicos. V. 2.3 ed., São Paulo: Saraiva

. Direito civil. Sucessões. 5 ed., Coimbra: Coimbra Editora, 2000.

OLIVEIRA, Guilherme de. O testamento: apontamentos, [S.1.]: Reproset [199?].

PALAZZO, Antonio. Testamento e istituti alternativi. Grandi questioni e pareri. Pádova: CEDAM Editore, 2008.

PORTUGAL. Acórdão do Supremo Tribunal de Justiça de 30 de janeiro de 2003. Disponível em www.dgsi.pt Acesso em 04.05.2012.

PORTUGAL. Acórdão do Supremo Tribunal de Justiça de 23 de setembro de 2008. Disponível em www.dgsi.pt Acesso em 04.05.2012.

PORTUGAL. Acórdão do Supremo Tribunal de Justiça de 13 de junho de 2007. Disponível em www.dgsi.pt. Acesso em 04.05.2012.

PORTUGAL. Acórdão do Supremo Tribunal de Justiça de 17 de abril de 2012. Disponível em www.dgsi.pt Acesso em 04.05.2012.

VAZ SERRA, Adriano. A revisão geral do Código Civil. In: Boletim da Faculdade de Direito da Universidade de Coimbra, XXII.

VASCONCELOS, Pedro Pais de. Teoria geral do direito civil. 4 ed., Coimbra: Almedina Editora, 2010. . A natureza das coisas. In: Estudos em homenagem ao Prof. Dr.

Manuel Gomes da Silva. Coimbra: Coimbra Editora, 2001. 